\title{
\#1034016573
}

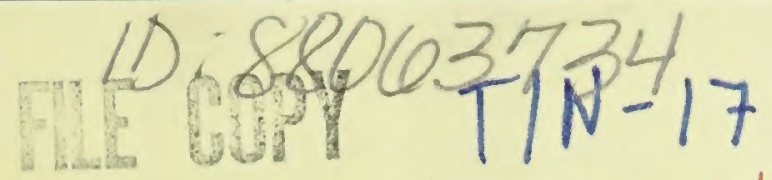

AS. DEATAMENT OF THE INTERIOR JREAU OF IAND MANAGEMENT $\# 1034016573$ TECHNICAL NOTE

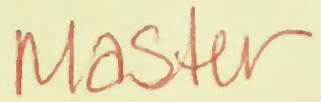

Filing Code $1525(\mathrm{P}-401)$

Date Issued October 1969

Bureau of Land Management U.S. DEPARTMENT OF THE INTERIOR

\section{CHEVROLET STAKE TRUCK TIRE CHAIN CLEARANCE}

The 1969 Chevrolets, Model C-30, with dual rear wheels do not have adequate clearance for installation of dual wheel tire chains (Classes 195, 196, 197, 198, and 199). Due to the clearance of less than 1.3 in. between the inside tire and spring, it will only be possible to install single tire chains on each outer dual wheel and tire. 
-

○

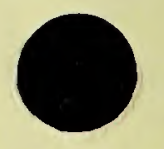

